\title{
VITAMINS B1 AND B12 DEFICIENCY AS A PREDICTOR OF TUBERCULOSIS SEVERITY AND PERIPHERAL NERVOUS SYSTEM DAMAGE
}

\author{
Shvets O. ${ }^{1}$, Shevchenko O. ${ }^{1}$, Piskur Z. ${ }^{2}$, Stepanenko H. ${ }^{1}$, Pohorielova O. ${ }^{1}$ \\ ${ }^{1}$ Kharkiv National Medical University, Ukraine \\ ${ }^{2}$ Danylo Halytsky Lviv National Medical University, Lviv, Ukraine \\ https://doi.org/10.35339/ic.7.4.184-187
}

\begin{abstract}
It is known that vitamin status plays one of the leading roles in the normal functioning of the immune system. Vitamins deficiency leads to weakening of immunity and can provoke occurrence of severe infectious diseases, including tuberculosis. The purpose of the study was to investigate the role of vitamins B1 and B12 deficiency as a predictor of tuberculosis severity and development of peripheral nervous system damage. Materials and methods. 89 patients with pulmonary tuberculosis and 12 healthy persons were included in the study. The patients were examined and treated according to current guidelines of the Ministry of Health of Ukraine. Additionally, the concentration of vitamins B1 and B12 was measured by ELISA in blood serum in all the patients at the treatment onset and in all healthy persons. To find the damage of peripheral nervous system we performed stimulation electroneuromyography of lower limbs. Results. The level of vitamin B12 was $0.19 \pm 0.01 \mathrm{nmol} / \mathrm{L}$ (median $-0.19 \mathrm{nmol} / \mathrm{L}$ ) in patients with destruction of the lung tissue and $0.22 \pm 0.01 \mathrm{nmol} / \mathrm{L}$ (median $-0.21 \mathrm{nmol} / \mathrm{L}$ ) in patients without destruction, $\mathrm{p}<0.05$. MNCV was $49.25 \pm 0.80 \mathrm{~mm} / \mathrm{s}($ median $-49.40 \mathrm{~mm} / \mathrm{s})$ in patients with destruction of the lung tissue and $53.41 \pm 0.99 \mathrm{~mm} / \mathrm{s}$ (median $-53.10 \mathrm{~mm} / \mathrm{s}$ ) in patients without destruction, $\mathrm{p}<0.01$. SNCV was $43.41 \pm 1.14 \mathrm{~mm} / \mathrm{s}$ (median $-42.05 \mathrm{~mm} / \mathrm{s}$ ) in patients with destruction of the lung tissue and $45.91 \pm 0.94 \mathrm{~mm} / \mathrm{s}$ (median $-46.00 \mathrm{~mm} / \mathrm{s}$ ) in patients without destruction, $\mathrm{p}<0.05$. Conclusions. Pulmonary tuberculosis leads to the disturbances in the metabolism of vitamins B1 and B12, causing their deficiency and the associated violation of impulse conduction along peripheral nerve fibers. More severe tuberculous lesions with destruction of lung tissue and massive bacterial excretion are associated with a more pronounced deficiency of vitamins B1 and B12, as well as decrease of motor and sensory conduction velocity.
\end{abstract}

Keywords: tuberculosis, vitamins, electroneuromyography, diagnosis.

\section{Introduction}

It is known that vitamin status plays one of the leading roles in the normal functioning of the immune system. Vitamins deficiency leads to weakening of immunity and can provoke occurrence of severe infectious diseases, including tuberculosis [1].

Some anti-tuberculosis drugs can affect vitamin metabolism, especially group B vitamins. Isoniazid, one of the most effective first-line drugs, is a derivative of hydrazine, which is

Corresponding Author:

Olha Pohorielova, MD, PhD student of the

Department of Phthisiology and Pulmonology,

Kharkiv National Medical University, Kharkiv, Ukraine.

E-mail: evildevilolga@gmail.com classified as a highly toxic substance of convulsive action. It inhibits synthesis of gamma-aminobutyric acid by inhibiting glutamic acid decarboxylase by antagonism with pyridoxal phosphate. By disrupting the exchange of vitamins of group B and glutamic acid, Isoniazid penetrates the bloodbrain barrier and produces a pronounced neurotoxic effect, which is manifested by the symptoms of damage to the central and peripheral nervous system [2]. Linezolid, an anti-tuberculosis drug widely used in the treatment of drug-resistant tuberculosis, causes adverse reactions in about $60 \%$ of cases. The most common of these are thrombocytopenia, irreversible peripheral neuropathy and optic neuropathy [3].

Meanwhile, group B vitamins play an important role in the pathogenesis of tuberculosis 
and the mechanisms of the anti-tuberculosis immune response formation. Thus, the study by $\mathrm{Hu} \mathrm{S}$ et al. [4] describes the important role of vitamin B1 in formation of the immune response, which shortens $M$. tuberculosis survival time in macrophages and in vivo through regulation of the proliferation activator receptor by gamma peroxide. Accordingly, vitamin B1 deficiency is associated with long-term survival, growth and reproduction of $M$. tuberculosis.

The study by S. Rempel et al. [5] shows that M. tuberculosis actively imports vitamin B12 which is necessary for its growth and development, thereby deepening its deficiency in patients with tuberculosis. Thus, the study of the deficiency of group B vitamins, namely vitamins B1 and B12, in tuberculosis patients, as well as the associated lesions of the peripheral nervous system, is an urgent issue.

\section{Purpose, subjects and methods:}

2.1. The purpose of the study was to investigate the role of vitamins B1 and B12 deficiency as a predictor of tuberculosis severity and development of peripheral nervous system damage.

\subsection{Subjects \& Methods}

89 patients with pulmonary tuberculosis and 12 healthy persons were included in the study. The patients were examined and treated according to the current guidelines of the Ministry of Health of Ukraine. Additionally, the concentration of vitamins B1 and B12 was measured by ELISA in blood serum in all the patients at the treatment onset and in all healthy persons. To find the damage of the peripheral nervous system we performed stimulation electroneuromyography of lower limbs. The function of $n$. tibialis $-m$. abductor hallucis (arch of the foot, stimulation at the level of the tarsus and popliteal fossa) and n. peroneus m. extensor digitorum brevis (the outer edge of the dorsum of the foot, stimulation at the level of the tarsus and popliteal fossa) was assessed. To assess motor and sensory conduction we measured motor nerve conduction velocity (MNCV), terminal motor latency (TML), sensor nerve conduction velocity (SNCV), terminal sensory latency (TSL). Statistical data processing was carried out using Statistica 8.0 with calculation of Mann-Whitney criterion and Spearman correlation coefficient.

\section{Conflict of interests}

The authors of the article declare no conflict of interest.

\section{Results \& discussion}

Comparison of vitamin B1 levels showed its significantly lower level in the tuberculosis patients
$(28.51 \pm 0.66 \mathrm{nmol} / \mathrm{L}$, median $-27.85 \mathrm{nmol} / \mathrm{L})$ than in the control group $(56.37 \pm 2.11 \mathrm{nmol} / \mathrm{L}$, median $56.45 \mathrm{nmol} / \mathrm{L}), \mathrm{p}<0.001$. When comparing the levels of vitamin B12, significantly lower values were also found in tuberculosis patients $(0.22 \pm$ $0.01 \mathrm{nmol} / \mathrm{L}$, median $-0.20 \mathrm{nmol} / \mathrm{L}$ ) than in control group $(0.29 \pm 0.01 \mathrm{nmol} / \mathrm{L}$, median $-0.29 \mathrm{nmol} / \mathrm{L})$, $\mathrm{p}<0.001$. The decrease in the level of vitamins B1 and B12 in patients with tuberculosis was accompanied by a decrease in the MNCV, which was $52.94 \pm 0.77 \mathrm{~mm} / \mathrm{s}$ (median $-51.00 \mathrm{~mm} / \mathrm{s})$ in tuberculosis patients and $60.87 \pm 0.91 \mathrm{~mm} / \mathrm{s}$ (median $-60.10 \mathrm{~mm} / \mathrm{s}$ ) in control group, as well as a decrease in the SNCV, which was $44.79 \pm$ $0.66 \mathrm{~mm} / \mathrm{s}($ median $-43.70 \mathrm{~mm} / \mathrm{s})$ in patients with tuberculosis and $57.22 \pm 1.61 \mathrm{~mm} / \mathrm{s}$ (median $59.50 \mathrm{~mm} / \mathrm{s}$ ) in control group, $\mathrm{p}<0.001$. Tuberculosis patients also had an increased TML up to $2.35 \pm 0.07 \mathrm{~ms}$ (median $-2.33 \mathrm{~ms}$ ) and TSL up to $2.37 \pm 0.08 \mathrm{~ms}$ (median $-2.40 \mathrm{~ms}$ ) compared with the control group in whom the TML and TSL were $1.84 \pm 0.10 \mathrm{~ms}$ (median $-1.80 \mathrm{~ms}$ ) and $1.71 \pm 0.11 \mathrm{~ms}$ (median $-1.75 \mathrm{~ms}$ ) respectively, $\mathrm{p}<0.001$.

When studying the dependence of the changes in the level of vitamins B1 and B12, as well as the degree of disturbances in the nerve fiber conduction, it was found that in the presence of destruction of the lung tissue, there is a significant decrease in the level of vitamin B12, as well as in the speed of conduction of the nerve impulses along the motor and sensory fibers compared with the patients without destruction of the lung tissue. Thus, the level of vitamin B12 was $0.19 \pm 0.01 \mathrm{nmol} / \mathrm{L}$ (median $-0.19 \mathrm{nmol} / \mathrm{L}$ ) in patients with destruction of the lung tissue and $0.22 \pm 0.01 \mathrm{nmol} / \mathrm{L}$ (median $0.21 \mathrm{nmol} / \mathrm{L}$ ) in patients without destruction, $\mathrm{p}<0.05$. $\mathrm{MNCV}$ was $49.25 \pm 0.80 \mathrm{~mm} / \mathrm{s}$ (median $-49.40 \mathrm{~mm} / \mathrm{s}$ ) in patients with destruction of the lung tissue and $53.41 \pm 0.99 \mathrm{~mm} / \mathrm{s}$ (median $-53.10 \mathrm{~mm} / \mathrm{s}$ ) in patients without destruction, $\mathrm{p}<0.01$. SNCV was $43.41 \pm 1.14 \mathrm{~mm} / \mathrm{s}$ (median $-42.05 \mathrm{~mm} / \mathrm{s}$ ) in patients with destruction of the lung tissue and $45.91 \pm 0.94 \mathrm{~mm} / \mathrm{s}$ (median $-46.00 \mathrm{~mm} / \mathrm{s}$ ) in patients without destruction, $p<0.05$. The data are presented in fig. 1 .

Correlation analysis showed significant negative correlations between the level of vitamin $\mathrm{B} 1$ and the massiveness of bacterial excretion detected by sputum microscopy $(\mathrm{r}=-0.40)$ and culture $(r=-0.34), p<0.05$. That is, the lower is the level of vitamin B1, the more massive is the bacterial excretion in the patient.

A negative correlation of the average strength $(r=-0.58, p<0.05)$ was revealed between MNCV and glucose level in patients with tuberculosis, fig. 2 . 

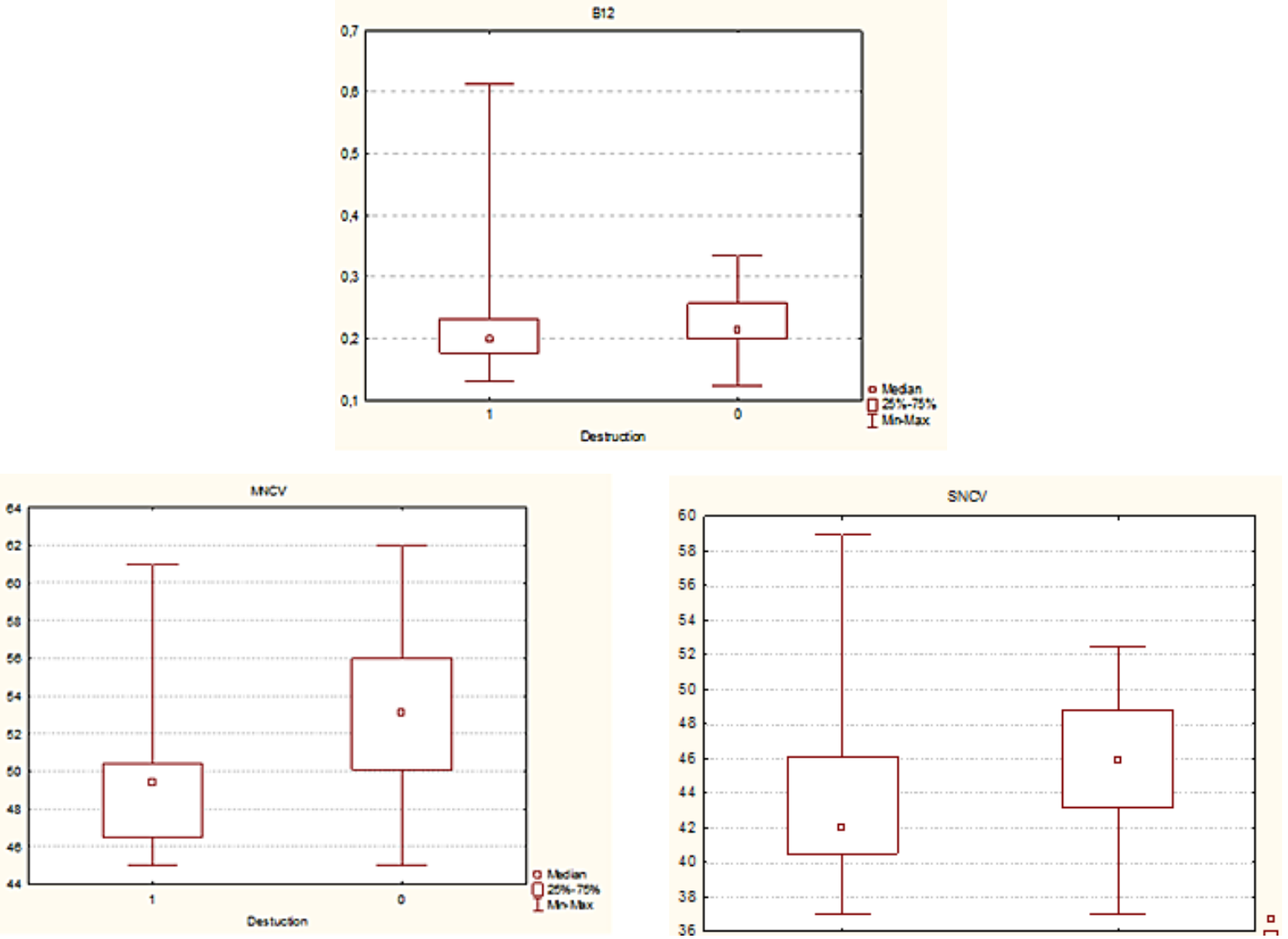

Fig. 1. Comparison of vitamin B12 levels and motor and sensory conduction velocity in patients with destruction of pulmonary tissue (1) and without it (0)

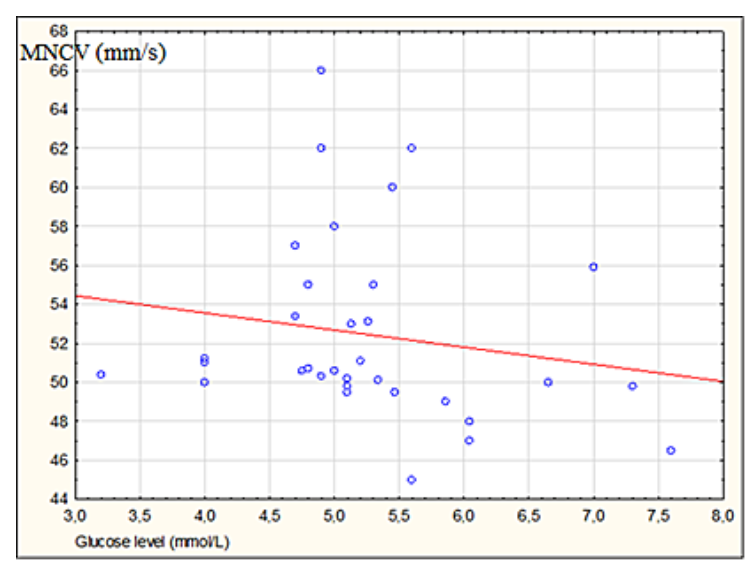

Fig. 2. Correlation between motor speed of conduction and glucose level in tuberculosis patients

Vitamin B1 takes part in oxidative decarboxylation of keto acids (pyruvic and lactic), synthesis of acetylcholine, which takes part in carbohydrate metabolism and associated energy, fat, protein, water-salt metabolism, in providing axonal transport, determines the regeneration of nervous tissue and the activity of the nervous system [6;7]. Vitamin B12 is essential in the formation of protein and fatty structures of the protective myelin layer of nerve fibers [8; 9]. Thus, according to the literature, vitamins B1 and B12 are important components that ensure the normal functioning of the peripheral nervous system.

Our study revealed a significant decrease in the levels of vitamins B1 and B12 in tuberculosis patients compared with healthy individuals. This decrease was accompanied by reduction in the motor and sensory conduction velocity and an increase in terminal motor and sensory latency. These can signal the onset of peripheral neuropathy in tuberculosis patients. With the neurotoxic effect of anti-tuberculosis drugs, it can be assumed that these disorders will further worsen during the treatment.

A correlations were found between the levels of vitamins B1 and B12, the motor and sensory conduction velocity and the severity of tuberculosis lesions (destruction of lung tissue and massive bacterial excretion). The correlation showed that the presence of destruction of the lung tissue is associated with a decrease in the level of vitamin $\mathrm{B} 12$ and is accompanied by a decrease in motor and sensory conduction velocity. Decreases level 
of vitamin B1 is associated with more massive bacterial excretion at the beginning of treatment.

Of particular interest is negative correlation between motor and sensory conduction velocity and the glucose level. In other words, the higher is the glycemic level, the slower the impulse is conducted in the peripheral nerve fibers. Previously, we have already identified a violation of the parameters of carbohydrate metabolism in patients with tuberculosis [10]. The combination of this factor with the neurotoxic effect of anti-tuberculosis drugs and the direct action of M. tuberculosis suggests the problem of vitamin deficiency and impaired functioning of the peripheral nervous system in patients with tuberculosis, aggravated during treatment, and recommends the appointment of vitamins of group B, in particular
B1 and B12, as an additional pathogenetic therapy in patients with pulmonary tuberculosis.

\section{Conclusions}

Pulmonary tuberculosis leads to the disturbances in the metabolism of vitamins B1 and B12, causing their deficiency and associated violation of impulse conduction along the peripheral nerve fibers. More severe tuberculous lesions with destruction of the lung tissue and massive bacterial excretion are associated with a more pronounced deficiency of vitamins B1 and $\mathrm{B} 12$, as well as a decrease of motor and sensory conduction velocity. The data obtained allow us to advise additional administration of vitamins B1 and B12 in the pathogenetic therapy of tuberculosis in order to prevent peripheral neuropathy development.

\section{References}

1. Semba, R.D., Darnton-Hill, I., de Pee, S. (2010). Addressing tuberculosis in the context of malnutrition and HIV coinfection. Food and Nutrition Bulletin, 31(4), 345-364. doi: 10.1177/ $15648265100314 \mathrm{~s} 404$

2. Mandel, M. (1959). Pyridoxine and the Isoniazid-induced neuropathy. Chest, 36(3), 293-296. doi: $10.1378 /$ chest.36.3.293

3. Rho, J.P., Sia, I.G., Crum, B.A., Dekutoski, M.B., Trousdale, R.T. (2004). Linezolid-associated peripheral neuropathy. Mayo Clinic Proceedings, 79(7), 927-930. doi: 10.4065/79.7.927

4. Hu, S., He, W., Du, X., Huang, Y., Fu, Y., Yang, Y., ..., Ma, L. (2018). Vitamin B1 helps to limit Mycobacterium tuberculosis growth via regulating innate immunity in a peroxisome proliferator-activated receptor-?-dependent manner. Frontiers in Immunology, 16(9), 1778. doi: 10.3389/fimmu.2018.01778.

5. Rempel, S., Gati, C., Nijland, M., Thangaratnarajah, C., Karyolaimos, A., de Gier, J.W., Slootboom, D.J. (2020). A mycobacterial ABC transporter mediates the uptake of hydrophilic compounds. Nature, 580, 409-412. doi: 10.1038/s41586-020-2072-8

6. Fattal-Valevski, A. (2011) Thiamine (Vitamin B1). Journal of Evidence-Based Complementary \& Alternative Medicine, 16(1), 12-20. doi: 0.1177/1533210110392941

7. Gochhayat, G., Kumar, M., Bhatt, S., Saini, V., Malik, A. (2019) Thiamine: A Key Role in Human Health. International Journal of Scientific \& Technology Research, 8(9), 42-51.

8. Nardone, R., Holler, Y., Storti, M., Christova, M., Tezzon, F., Golaszewski, S., ..., Brigo, F. (2013) Thiamine Deficiency Induced Neurochemical,Neuroanatomical, and Neuropsychological Alterations: a Reappraisal. The Scientific World Journal, 1-8. doi: /10.1155/2013/309143

9. Nouri, A., Patel, K., Montejo, J., Nasser, R., Gimbel, D.A., Sciubba, D.M. Cheng, J.S. The Role of Vitamin B12 in the Managementand Optimization of Treatment in PatientsWith Degenerative Cervical Myelopathy. Global Spine Journal, 9(3), 331-337. doi: 10.1177/2192568218758633

10. Shvets, O.M., Shevchenko, O.S. (2019) Effect of antituberculosis treatment on dynamics of carbohydrate and lipid profile. Tuberculosis, Lung Diseases, HIV-Infection, 2(37), 35-40. doi: .30978/ TB2019-2-35

Received: 03-Sep-2020

Accepted: 11-Dec-2020 